\title{
SimpliciDIY - Do-it-yourself wood building system
}

\section{SIGRADI2018 TECHNOPOLITICAS \\ xxii congresso da sociedade iberoamericana de gráfica digital 22th conference of the iberoamerican society of digital graphics 07|08|09|novembro|2018 iau usp | são carlos | sp br}

\author{
Max Salzberger \\ Technische Hochschule Köln | Germany | salzberger@slow.cc \\ Michael Lautwein \\ Technische Hochschule Köln | Germany | michael.lautwein@th-koeln.de
}

\begin{abstract}
Worldwide there is a big need for affordable livingspace. Globalization leads to a connection of development and ideas in the field of building. Open Source communities could improve and accelerate this development. The potential of theses communities lies in the connection of different diciplines. Especially for building projects with a small budget and a willingness to participate in the work process open source do-it-yourself constructions are a great opportunity to help cover the need of affordable work and living space. Renewable materials such as wood offer great potential here. New, standardised technologies make a decentralised production possible.
\end{abstract}

Keywords: Open source; Do it yourself; Wood construction; Bottom up; Affordable livingspace.

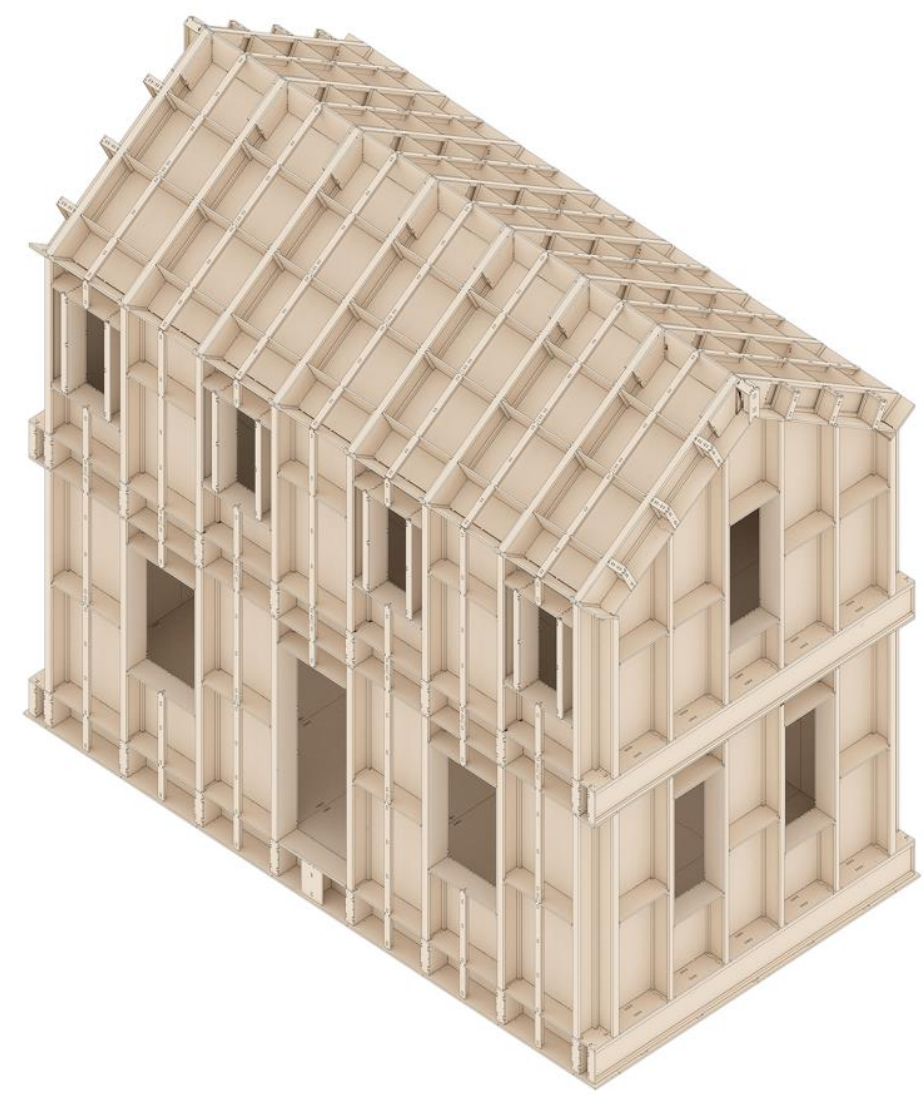

Figure 1: Phenotype of the System SimpliciDIY. Source: Authors.

\section{INTRODUCTION}

Our Open Source Building System SimpliciDIY has been developed against this background. The elements of the house are produced by a CNC milling machine and can be joined on site without mechanical support. A manual allows the user to build the house himself without special training. The authors realized the project at the interface between architecture and crafts, they work as carpenters, lecturers of digital fabrication and prospective architects. 


\section{ENVIRONMENTALLY RESPONSIBLE BEHAVIOR}

The technologies and building materials currently used in construction are speeding up climate changes as construction activity increases. A sustainable approach is therefore necessary to cope with the shortage of housing. Which material ressources we use is of decisive importance. From an ecological point of view, the use of wood must be underlined. The positive environmental impact of wood-based materials helps to reduce the carbon dioxide $\left(\mathrm{CO}^{2}\right)$ content in the atmosphere. The use of wood in the building industry removes the $\mathrm{CO}^{2}$, which is stored in the wood through photosynthesis from the earth's atmosphere for the lifespan of the building. It is therefore important to choose timber constructions with the longest possible lifespan. In addition to the environmental aspects, wooden building materials are characterised by their resistance and worldwide availability.

\section{WOODEN PANEL}

The aim of this work is to develop a building system for self-construction from wood materials. The materialspecific advantages of panel materials are used as the material for the primary supporting structure. Due to the industrial, standardized manufacturing process, the material is characterized by a constant quality, higher dimensional stability and strength compared to solid wood. Besides its technical properties, it is easy to process. These factors qualify the material for digital design and production technology.

\section{ROLE OF THE ARCHITECT}

The present challenges for an architect go far beyond the three main requirements for architecture, strength (Firmitas), usefulness (Utilitas) and beauty (Venustas) which were defined by the roman architect Vitruv. Every architect has a responsibility towards the urban landscape, the environment, the people and the human health. He should always act on the principles of avoiding damage and be aware of the impact of his built work on the environment.

At the moment, building activities are clearly separated into many sub-areas and the architect has to deal with increasingly complex building processes. The original design process for an architect is almost non-existent in daily business. In a construction system, the architect as developer would be responsible for all areas of the construction process and would be involved in the entire design process. Many different trades are already an integral part of the planning phase of a building system. Many aspects that are necessary for the further construction phase are already clarified during the planning process.

\footnotetext{
"At a time when our population and the consequent demands for space and services continue to grow, when cities expand and, as is frequently suggested, buildings account for more than half of the energy consumed in the world, clearly both the number and nature of roles for the architect are increasing. However, these can be characterized as roles that the architect could and should not play in glorious isolation, but rather by working closely with other specialists. This would not only make it possible to develop integrative design proposals, but also enable architects to play more influential roles in the development of inspired proposals for the design, construction, operation
}

and management of buildings." (Carter, 2010, from, Stotjesdijk, Digital Design \& Digital Fabrication, 45-46)

The quote by Brian Carter clarifies that the tasks for a professional and responsible designer in the future will increasingly be shaped by showing sustainable solutions. Access to housing should be granted to all classes of society. The architect should therefore dedicate himself more to the development of processes and systems that can be adapted by non-professionals. For architects, this previously completely ignored field of planning opens up new possibilities.

In the development of a building system, the architect has to deal intensively not only with the design but also with the construction and the suitable materialization. The specific properties and directional strengths of the panel materials are essential in the planning for the primary construction. A direct connection between architecture and construction can lead to a more effective design of living space, to avoid mistakes and to reduce factors that increase costs. The development of building systems made of wood and the production with modern manufacturing techniques offers the opportunity to slim down the complex processes on the building site.

\section{DIY - DO IT YOURSELF}

Do it yourself solutions have established in almost all areas of society. In the construction sector there are currently no DIY-systems available, but the potential for appropriate solutions is immense.

A building system that implies the individual work of the users is primarily relevant in residential construction or for small office structures. The supply of these systems also gives private people with limited financial budgets and a willingness to do something on their own the access to affordable and sustainable office and residential space. The systems can also be used in social housing or development aid.

A freely accessible building system made of panel materials should use the core aspects of digital production, independence of quantity, efficiency and costoptimized processes. The simple assembly of the structure should be a decisive factor in the form finding process of a self-made system. Complex shapes can be a hindrance in the further construction process. The complexity of a building system influences costs and determines user acceptance and satisfaction while using.

\section{BOTTOM UP}

"It is just as easy and cost effective for a CNC milling machine to produce 1000 unique objects as to produce 1000 identical ones." (Kolarevic, 2005, 84)

The invention of CAD and later BIM systems enables a file-to-factory workflow. Planning data can be sent directly to production and components or entire buildings can be produced on the basis of this information. For digital production, the standardized data format makes no difference whether the order comes from a globally active business enterprise or a private individual, and it no longer makes any difference whether the product is custom-made or mass production. So the consumer can change from a pure consumer to a producer. This means that the design process no longer approaches the "top 
down" from the big to the small but develops the design into a "bottom up".

\section{OPEN SOURCE AND THE GENIUS LOCI}

How can the "genius loci" of a place be preserved when an unskilled person as a user of a building system becomes a designer? In architecture, the Genius Loci describes the >spirit of a place $<$. This means the professional planer should consider the design-relevant structural specifications as well as the characteristics of a location, while planning a structure. With an open source construction system, however, the developer of a system passes these decisions on to the future user. The user has to decide all design relevant aspects himself, which have been previously handled by a professional planner.

"Open Architecture Network - which replaces traditonal copyrights restrictions with Creative Commons licensing and allows open access to blueprints." (Ratti and Claudel, 2015, 122)

The architect Cameran Sinclair pursued the idea of sustainable and easily accessible building systems for doit-yourself construction as early as 1999. With the Open Architecture Network, he wanted to create affordable living space for all social groups through individual contributions. With a freely accessible construction system, it can be assumed that many users are also nonprofessionals in the construction sector and have no experience in the planning of construction works.

Software solutions can help the user of a freely accessible building system to clarify some of these questions. For example, the influence of a developed building shape and the orientation of the window openings on the building climate could be simulated and made visible to the user. The influence of each change on the total costs can also be made visible. However, it is difficult for the layman to define the requirements for his own building and to estimate the effect on the particular location due to the lack of experience. Errors in this process phase should be avoided by the consulting role of a professional planner.

Slimmed down processes offer the possibility of involving the architect as a consultant at the design-relevant points. For many people it is too cost-intensive to finance an architect for the entire construction process. Hourly financing for design issues is one way to save costs. However, to involve the architect only in stages of the construction process requires a change in the liability of architects.

"As the elements have different shapes and characteristics
that have to fit together like a large scale puzzle, in many
cases there is only one way to join them correctly...This
gives the architect more influence on the quality of the final
building. At the same time, he has a greater responsibility for
the correctness of his drawings and descriptions."
(Brendeland and Kristoffersen, 2009, from Arch + Holz, 34)

The architect as the designer of the system has a significant impact on the quality of the resulting object. The responsibility to achieve error-free planning in the creation of the individual system parts and to define the planning limits and variation possibilities is immensely higher. Brendeland and Kristoffersen also mention the importance of an assembly instruction, which should be an elementary part during the development of a do-ityourself building system.

In poorly developed regions, many people cannot afford the individual consulting services of an architect. Especially in theses regions is a high demand for affordable living space. In addition to the assembly instructions, a design manual could then be helpful. The task of a design committee should be to produce the design instructions in accordance with local conditions. The aim of this guide was to sensitize the user to the effect of architecture on the environment.

\section{METADESIGN}

Planning tools such as the component-oriented softwarelogic BIM enables the planner to determine numerous aspects from a digital model that are necessary in the further construction process. Many variations can be generated from the digital model of a building system with the help of parametric software solutions, by previously defined affecting parameters. Changes can be simulated in real time and design variants can be checked for their actual physical usability of a system. If necessary, the architect can directly involve other professional planners in the design process via the digital model.

\begin{abstract}
"There is a demand for that [digital frameworks for masscustomization] now in architecture firms because we need to have designs that will be suitable for different contexts, but are within the same general family. So we need to produce a metadesign that we can adapt or changing circumstances. I'm convinced that this is the wave of the future." (Knight, 2003, from Stoutjesdijk, Digital Design \& Digital Fabrication)
\end{abstract}

A building system should always be based on a basic framework, as Knight describes it, the "Metadesign". The basic framework of a building system made of panel materials is restricted by constructional limitations. These can have an effect on the number of floors, the span of a slab beam, the number of wall openings, the distance between columns, the material, the material thickness, etc.

The basic framework for a building system is not linked to a specific location. Rather, the metadesign can be adapted to many fields of application and local factors, which reduces development costs.

Parameters can be understood as adjustment screws of the building system and influence the characteristics of the building. When parameters are defined, they must be prioritized. Some parameters have a greater influence on the overall structure than others. When the size of a building is changed, this has an impact on space efficiency, the construction costs, operating and maintenance costs, land use, resource consumption and many other factors depend on it. Therefore, the parameters with great leverage should first be adapted.

The metadesign can be adapted by a professional planner to the changing circumstances at the particular place of use by previously defined rules. The rules allow a number of design variations within the given limits.

\section{DEMOCRATIZATION OF PRODUCTION}

"Fabrication is not a modelling technique, but a revolution in the making of architecture. The new structuralism

3 
designates the cultural turn away from formalism and towards a material practice open to ecological potential."

(Rivka und Robert Oxman, from Stoutjesdijk, 2010, 43)

The digital model used for the design and simulation process can also provide the manufacturing parameters for fabrication. This bridges the gap between design and production.

There is a growing number of open workshops worldwide, so-called FabLabs or Maker Spaces. Private individuals have access to professional manufacturing machines. The idea of open workshops also offers great potential in the development of structurally weak regions and in the area of development aid. The provision of manufacturing laboratories with industrial production capacities offers the possibility to manufacture or repair products ourselves according to local requirements.

\section{PERSPECTIVE}

Chris Anderson even argues in his book Makers that in the future industrial giants can be replaced by thousands of small companies covering niche markets. He also sees an opportunity for local manufacturing without relocating it abroad due to excessive labour costs. Due to automation, the labour costs regarding the production of a product are low, factors such as the duration and costs of transport are therefore more important again. In the case of products that are purchased over long transport routes, storage costs for sufficient stockpiling of this product are also of importance. These costs can be reduced by local production.

\section{ANALYSIS}

For the planning of the primary load-bearing structure of a building system, five selected building systems were considered during the analysis, from the design to the construction of the primary load-bearing structure including the installation of insulation and air-tightness level. The findings of this analysis form the basis for the subsequent development of a system.

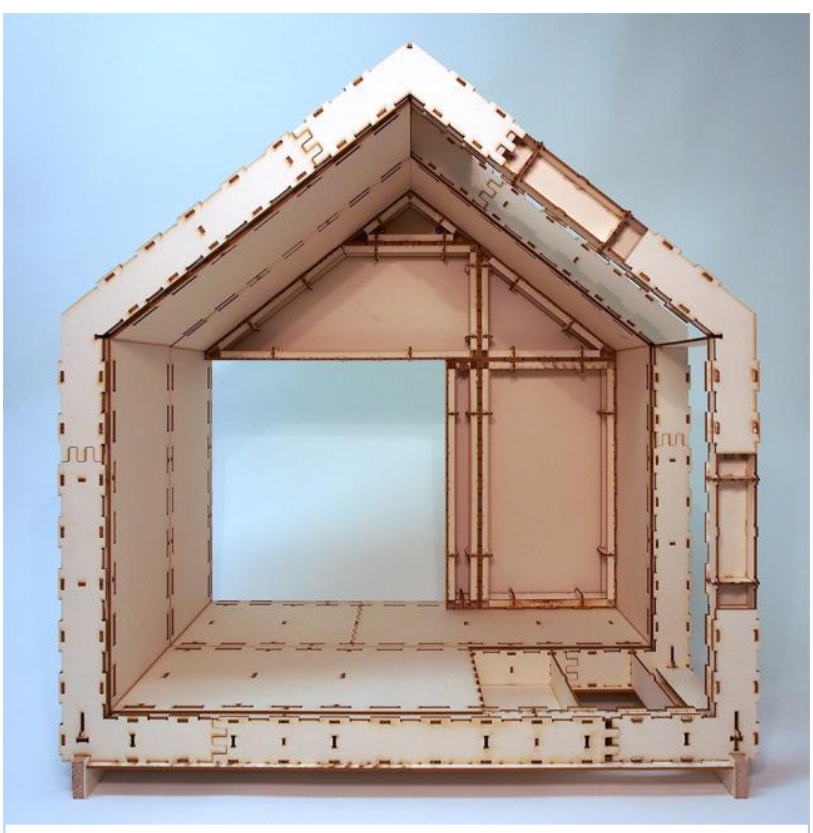

Figure 2: Model of the analyzed Wren-System in Scale 1:7. Source: Authors.

\section{PHYSICAL MODEL}

The analysis of the building systems was based on close examination of the construction process, a digital and physical model in a 1:7 scale. The findings from the first part of the work formed the basis of the evaluation matrix used to evaluate the five systems. Technically measurable parameters were determined from the digital model using a grasshopper-script. The evaluation of the other parameters, in particular the assembly by the user, was carried out using the physical model.

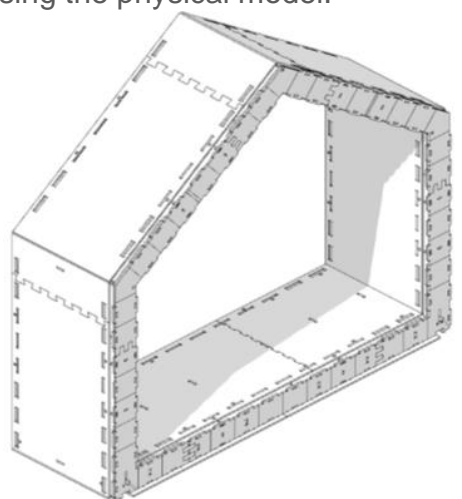

Figure 3: Digital Model used for evaluation. Source: Authors.

\section{ANALYSIS TOOL}

We programmed a Grasshopper script for analyzing the technical values. The parameters were clearly defined in advance. They are divided into the different phases of the construction process, design, material, production, transport, assembly and use. A differentiated assessment was made by weighting the parameters with a focus on self-construction.

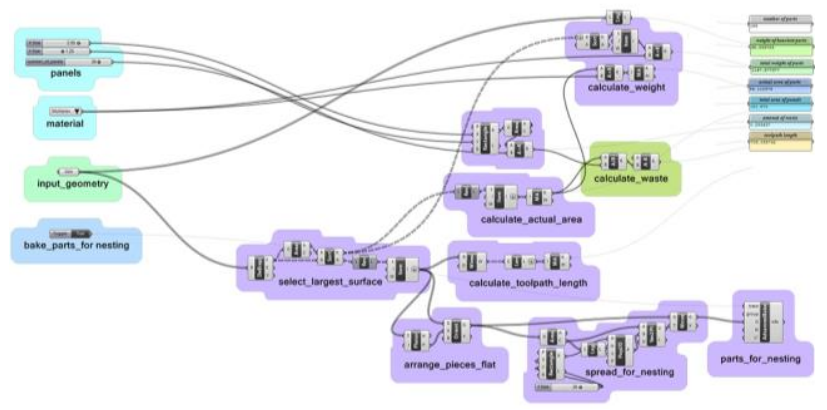

Figure 4: excerpt of the grashopper script. Source: Authors.

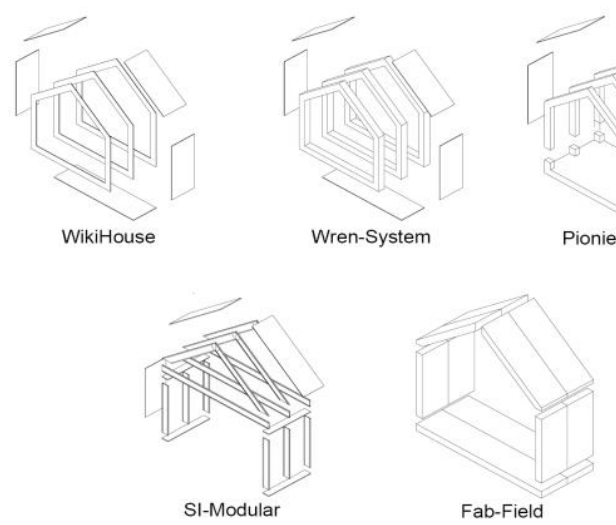

Figure 5: five systems analyzed. Source: Authors 


\section{RESULTS}

Table 1: evaluation of systems

\begin{tabular}{|c|c|c|c|c|c|c|c|}
\hline & 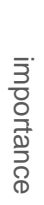 & 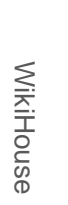 & 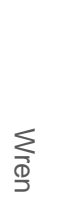 & 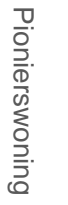 & 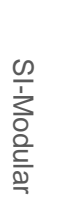 & $\begin{array}{l}\frac{T}{0} \\
\frac{0}{0} \\
\frac{1}{0} \\
\frac{\Phi}{2}\end{array}$ & 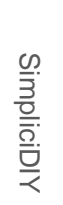 \\
\hline Design & & 25 & 78 & 84 & 59 & 44 & 84 \\
\hline $\begin{array}{l}\text { Storeys } \\
\text { Combination }\end{array}$ & + & 25 & 10 & 0 & 75 & 50 & 100 \\
\hline Subsystems & + & 25 & 75 & 75 & 50 & 50 & 75 \\
\hline Design diversity & 0 & 25 & 50 & 75 & 50 & 25 & 75 \\
\hline Material & & 38 & 44 & 56 & 63 & 56 & 75 \\
\hline Quantity of material & 0 & 25 & 50 & 75 & 50 & 50 & 75 \\
\hline Cost of material & 0 & 25 & 25 & 75 & 50 & 50 & 75 \\
\hline Waste material & 0 & 50 & 50 & 25 & 75 & 75 & 75 \\
\hline Choice of material & 0 & 50 & 50 & 50 & 75 & 50 & 75 \\
\hline Production & & 77 & 82 & 82 & 41 & 55 & 80 \\
\hline Level of automation & 0 & 75 & 75 & 75 & 50 & 75 & 75 \\
\hline $\begin{array}{l}\text { Length milling paths } \\
\text { Complexity of }\end{array}$ & 0 & 50 & 50 & 50 & 50 & 25 & 75 \\
\hline processing & 0 & 100 & 100 & 100 & 25 & 75 & 100 \\
\hline Size of material & + & 100 & 100 & 100 & 50 & 50 & 75 \\
\hline Mounting the parts & 0 & 50 & 75 & 75 & 25 & 50 & 75 \\
\hline Transport & & 50 & 63 & 63 & 75 & 88 & 75 \\
\hline $\begin{array}{l}\text { Susceptibility of } \\
\text { parts }\end{array}$ & - & 25 & 50 & 50 & 75 & 100 & 75 \\
\hline Loading efficiency & - & 75 & 75 & 75 & 75 & 75 & 75 \\
\hline Assembly & & 50 & 44 & 39 & 81 & 64 & 73 \\
\hline Tools and aids & 0 & 50 & 50 & 50 & 75 & 50 & 50 \\
\hline People & 0 & 50 & 25 & 25 & 75 & 50 & 75 \\
\hline Handling & + & 50 & 25 & 0 & 75 & 50 & 75 \\
\hline $\begin{array}{l}\text { Assembly time } \\
\text { Complexitiy of }\end{array}$ & + & 75 & 50 & 25 & 50 & 25 & 50 \\
\hline assembly & + & 100 & 25 & 25 & 100 & 75 & 75 \\
\hline $\begin{array}{l}\text { Assembly time } \\
\text { Functionality }\end{array}$ & + & 25 & 25 & 50 & 100 & 100 & 75 \\
\hline connections & + & 25 & 100 & 100 & 100 & 100 & 100 \\
\hline Number of parts & 0 & 50 & 75 & 50 & 75 & 25 & 75 \\
\hline Level of repetition & + & 50 & 25 & 25 & 75 & 75 & 75 \\
\hline Utilization & & 42 & 47 & 72 & 67 & 50 & 83 \\
\hline $\begin{array}{l}\text { Accessibility } \\
\text { structure }\end{array}$ & - & 50 & 25 & 25 & 75 & 50 & 75 \\
\hline Lifespan & + & 100 & 75 & 100 & 75 & 75 & 100 \\
\hline Reversibility & + & 75 & 25 & 75 & 50 & 25 & 75 \\
\hline Adaptivity & 0 & 50 & 50 & 50 & 75 & 50 & 75 \\
\hline Total & & 45 & 51 & 53 & 57 & 50 & 68 \\
\hline
\end{tabular}

\section{CONCLUSION OF ANALYSIS}

The advantages of a construction system lie in its flexibility and adaptability to different requirements. Open building systems such as WikiHouse allow the combination with subsystems, systems with a component catalogue limit the variation possibilities. Parametric systems in particular offer a high degree of design diversity; data prepared for a digital process chain in standardized formats allows local and cost-effective production. The degree of prefabrication has an influence on the production and assembly process. The best possibility for the user to become active himself is when assembling the structure. It is influenced by the handling of the individual components and the complexity of the system. A high repetition of the components reduces the complexity, the resolution of the supporting structure in components facilitates handling. Efficient installation allows the sealing layer to be applied quickly, which is indispensable to protect wooden constructions from the weather.

The resolution of the load-bearing structure into linear components, which are joined by standardized connections, has proven to be beneficial. A parts catalogue facilitates the creation of system statics. For the development of SimpliciDIY the standardized connectors were replaced by parametrically configurable ones. This allows the individual adaptation of the design to the requirements of the users as well as to local conditions. The architect has a consulting function in the design process. The pre-assembly of the elements from the factory is minimized to reduce costs, the limitation of the material size allows a large variety of producers and therefore a local production. This is optimized by the use of standardized components like I-beams that are globally available and which do not require any machining. This also facilitates the creation of system statics, which further saves costs. All components are reversibly connected to ensure the system's adaptability and reversibility.

\section{DEVELOPMENT}

\section{METHODS}

After evaluation of the analysis and evaluation of the investigation, the platform-frame principle was chosen for SimpliciDIY. Due to the dimensions of the components and the assembly sequence, it is ideally suited for the rapid erection of a supporting structure in selfconstruction. Based on the design principle and the assembly sequence, several static principles were tested and the most suitable one selected. Defined spans and energetic characteristics were used to pre-dimension the linear components. Installation requirements and ecological considerations led to the use of injection insulation.

This was succeeded by the definition of the nodes of the system, their function and the resulting requirements, as well as the definition of the criteria for evaluating the development. The criterias production, number of components, degree of repetition, handling of the components, pre-assembly, joining, complexity and functionality, as well as the corresponding matrix result from the analysis. The individual joints of the system were developed in an iterative process until all criteria were fulfilled. The individual development stages were continuously checked and evaluated during the process using digital and physical models on a scale of $1: 7$ to $1: 1$ Subsequently, the overall system was evaluated using the evaluation matrix. The evaluation was based on a digital model and a 1:1 scale prototype, which was produced in 
the laboratory for experimental building at the Technical University.

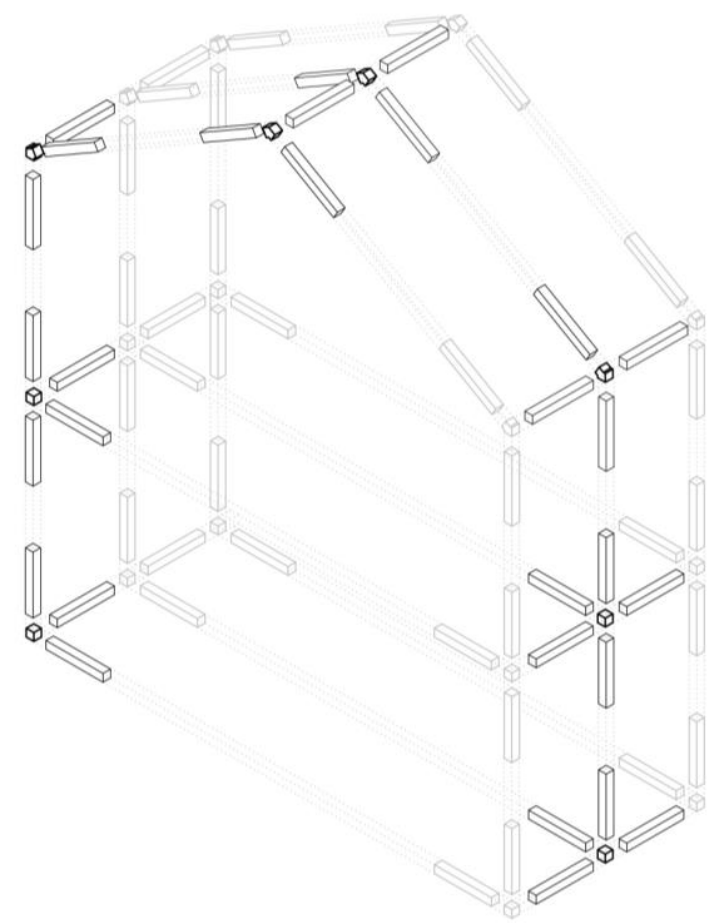

Figure 6: Concept sketch of construction principle. Source: Authors.

\section{RESULTS}

The load-bearing structure consists of the linear elements of the I-beams, which form the floor and ceiling beams, wall supports and rafters. The web girder is characterized by high load-bearing capacity and material-saving and thermal bridge-optimized construction. The joints connecting the linear elements are made of laminated veneer boards. The wall structure - with an inner panelling made of ESB and soft wood fiber boards on the outside is open to vapor diffusion. No adhesive bonds are used when connecting the components, all bonds are reversible. Two-story buildings with different roof pitches can be realized. The use of structurally tested semifinished products facilitates the creation of system statics and enables flexible adaptation to the needs of the users. An assembly instruction guarantees the assembly in selfconstruction.

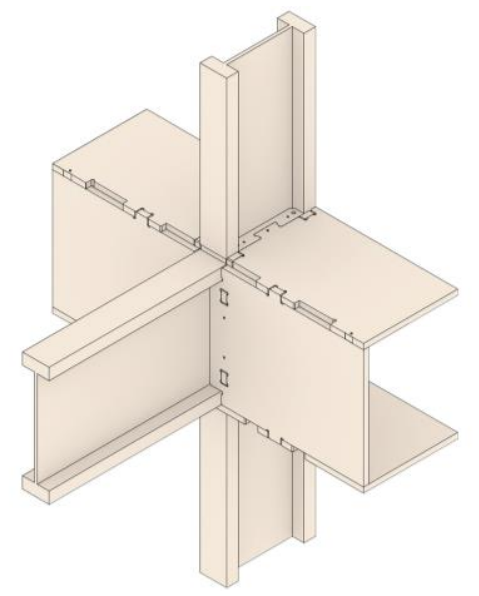

Figure 7: joint connecting ground and first floor. Source: Authors.

\section{CONCLUSION OF DEVELOPMENT}

SimpliciDIY allows a high degree of individualization and a variable design of the cubature with single and multistorey design and different roof shapes. A variable axis grid and the scalability of the system are achieved by adapting the joints and using I-beams. The design as an open system allows a high degree of integration of subsystems. Due to the static parameters of the I-beams, the primary supporting structure can be erected in a material and cost-saving manner.

The production parameters of the system are designed for the circumstances of a local production. Standardized Ibeams are cut to length at the factory, machining is no longer necessary. All other elements of the system can be fabricated from small format panels $(2.5 \times 1.5 \mathrm{~m})$. These do not impose high demands on the dimensions and equipment of the production machines.

The assembly allows the largest contribution of own work. The reduced depth of prefabrication saves costs for the user. The tools required for setting up the primary support structure are limited to a hammer and a cordless screwdriver: All components are delivered to the construction site pre-produced, no further machining is necessary. The dimensions of the components allow preassembly in a weatherproof location and storage in a standardized construction site container. The reduced complexity of the system has a decisive effect on the assembly process. The small number of parts and the high repetition of the steps facilitate and accelerate the pre-assembly and joining of the parts into the system. All required assembly aids are integrated into the system. Due to the dimensions and low weight of the components and elements, the final assembly can be carried out by a maximum of three persons, which facilitates the site organization. Heavy machines are not required; in the case of two-story buildings, the erection of scaffolding is recommended. The high degree of interlocking of the elements already leads to a form-fit connection during the joining process, the force-locking screw connection fixes the elements in a highly functional manner.

The supporting structure is permanently protected against condensation damage by the breathable wall construction. The base plate with few joints and a sealing sheet protects against rising damp. The accessibility of the supporting structure is given by the elimination of adhesive connections, but can be made more complicated by the wall construction and the associated substructure. Adaptivity during the utilisation phase is given, extensions and additions to the supporting structure are possible. Material separation and return of the building materials into the material cycle is guaranteed at the end of the utilisation phase.

SimpliciDIY shows that timber construction systems for do-it-yourself construction with standardized production methods using industrial products available worldwide can provide a solution to the need for sustainable and affordable office and residential buildings. 

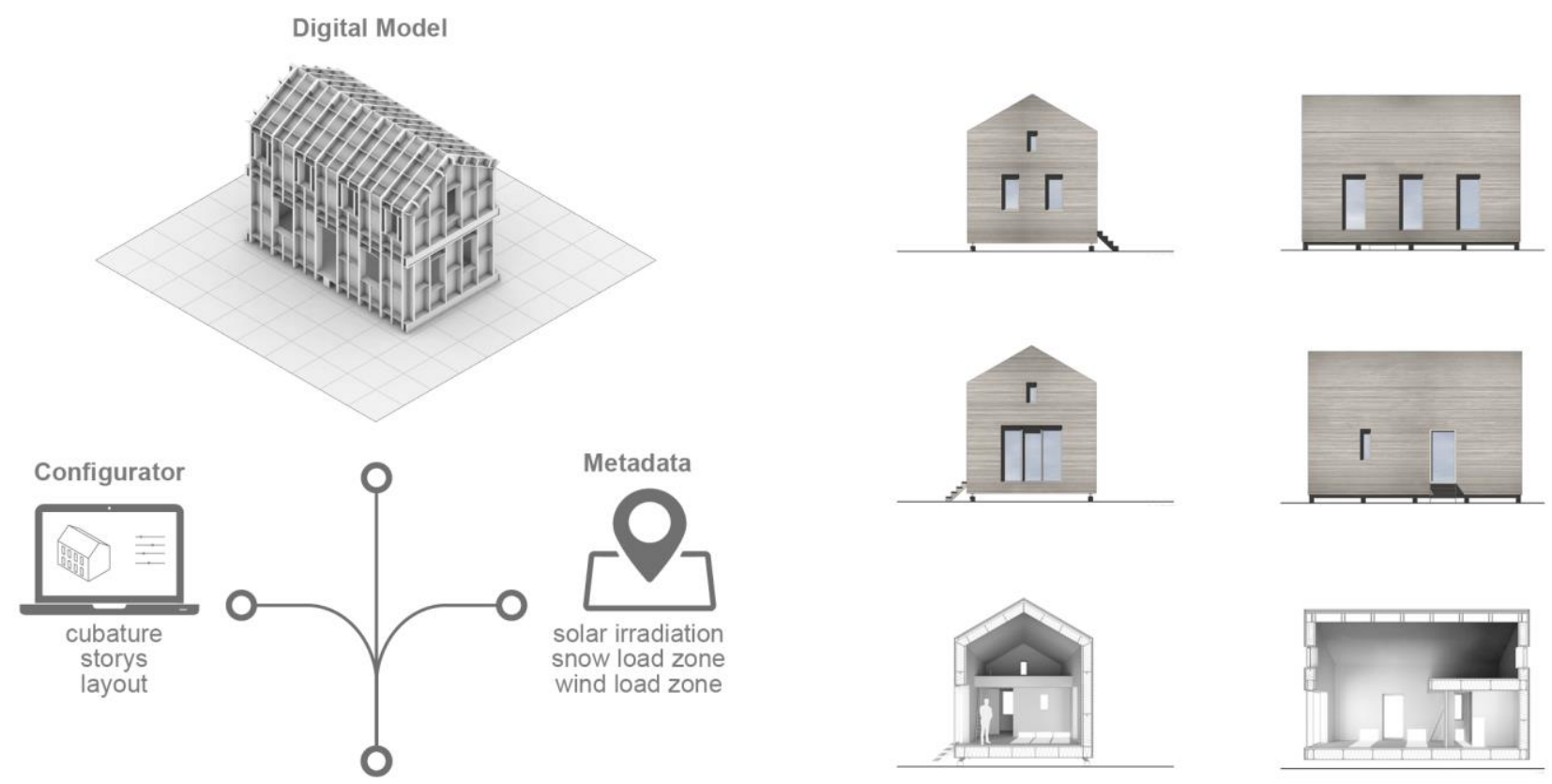

Customization of components
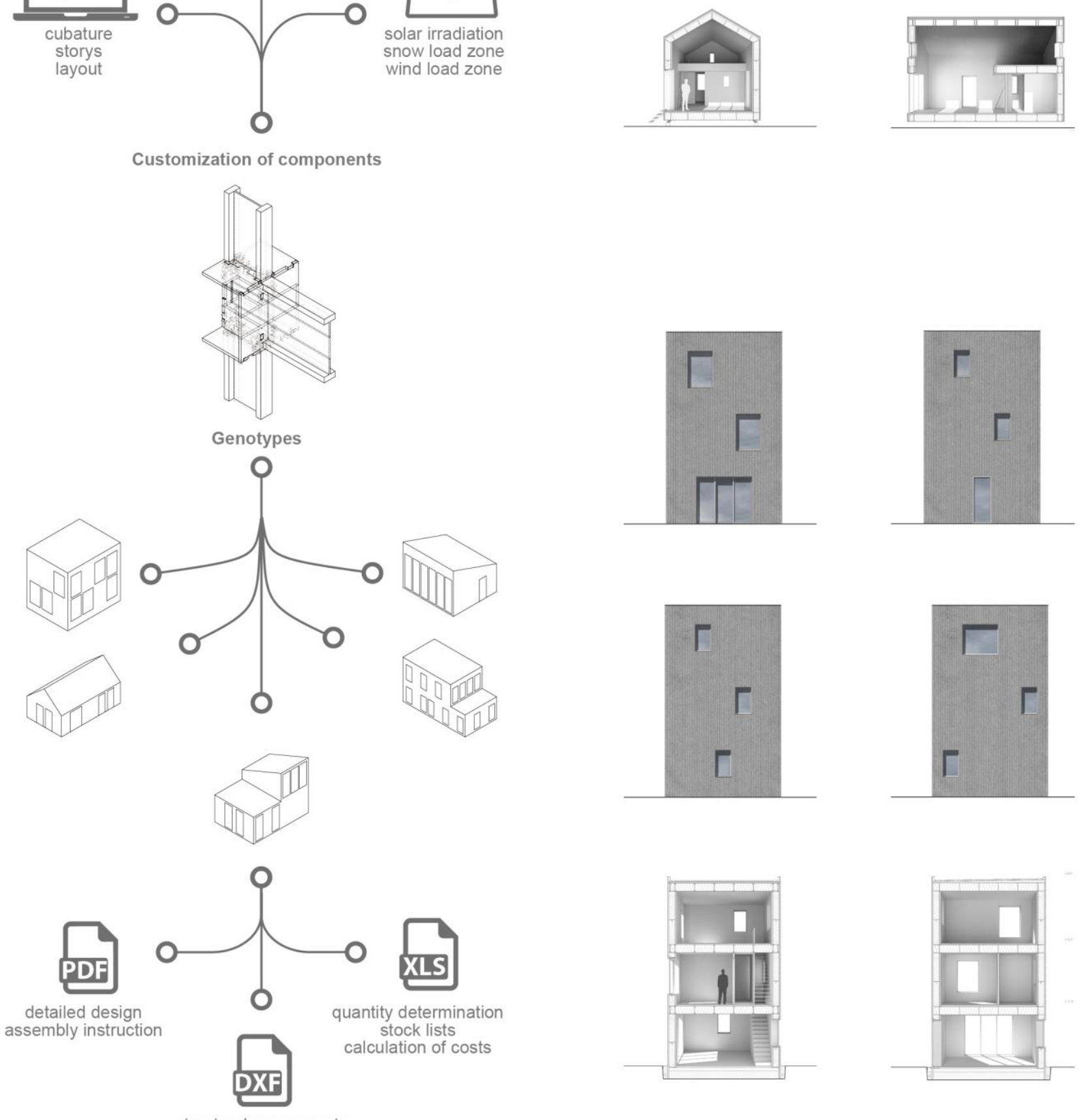

structural components

Figure 8: process chain from design to production. Source: Authors.

Figure 9: examples of genotypes possible with SimpliciDIY. Source: Authors. 


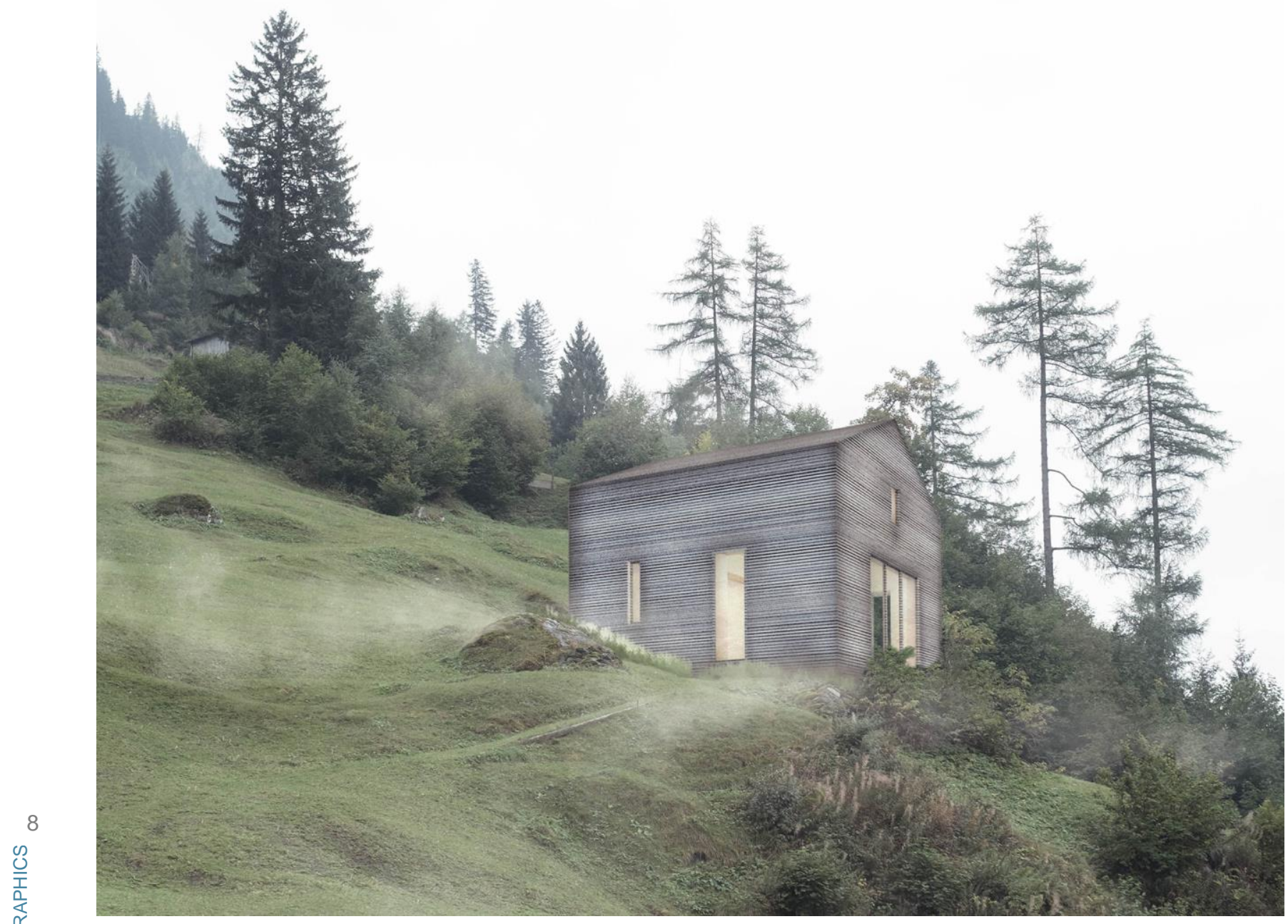

Figure 10: Genotype Retreat. Source: Authors.

\section{DISCUSSION}

Residential property may not only be accessible to an elitist part of the society. The system which has been developed is intended to make the building process more democratic and allow the layman easy accesss to affordable and sustainable living space. All insights gained in the project are available for free to the public and are meant to encourage discussion.

\section{ACKNOWLEDGMENTS}

In the analysis of existing systems using wood the systems of Wikihouse, Pionierswoning, Fabfield and SIModular have been investigated. The project was supported by structural, building and wood engineers. The prototypes of the system have been produced in the laboratories of the university. Partners in industry provided the necessary materials.

\section{REFERENCES}

The authors contributed equally to this work as co-first authors.

Anderson C. (2012). Makers. the new industrial revolution. New York, Crown Business
Arch+ Verlag Gmbh. Kuhnert. Kraft. Ngo. Schindler. Hirschler (2009) Arch + Holz. Aachen

Düchs M. (2011). Architektur für ein gutes Leben über Verantwortung Ethik und Moral des Architekten. Münster. Waxmann

Green M., Taggart J.(2017). Hoch Bauen mit Holz - Technologie. Material. Anwendung. Basel. Birkhauser

Hauschild M. and Karzel R. (2010). Digitale Prozesse: Planung,Gestaltung, Fertigung. München. Edition Detail

Kaufmann H. Krotsch S. and Winter S. (2017). Atlas Mehrgeschossiger Holzbau. München. Detail

Kolarevic B. (2005) Architecture in the digital age designing and manufacturing. Taylor \&Franci Ltd.London

Menges A., Schwinn T. and Krieg O. (2017). Advancing wood architecture: a computational approach. New York. Routledge

Nerdinger, W. (2010). Wendepunkte im Bauen: Von der seriellen zur digitalen Architektur. Muüchen. Detail

Ratti C. (2015) Open Source Architecture. London. Thames \& Hudson Ltd

Stoutjesdijk P. (2010). Digital Design \& Digital Fabrication. Delft. TU Delft Library 